Associations amongst response inhibition, motivational beliefs, and task persistence in early elementary school

\author{
Sarah Jo Torgrimson ${ }^{1}$, Patricia Tan $^{2}$, \& Jennie K. Grammer ${ }^{1}$ \\ ${ }^{1}$ School of Education \& Information Studies, University of California, Los Angeles, ${ }^{2}$ Department \\ of Psychiatry, UCLA David Geffen School of Medicine
}

Manuscript In-Press at Journal of Experimental Child Psychology

Corresponding Author: Sarah Jo Torgrimson (sjtorgrimson@ucla.edu)

Declarations of Interest: None. 


\begin{abstract}
Task persistence is an important learning-related behavior associated with academic success. Although persistence has been related to motivational beliefs and cognitive skills, these constructs are typically studied independently, limiting our understanding of relations among them. The current investigation was designed to understand how these concepts related in early elementary school, a developmental period characterized by high motivational beliefs, growth in cognitive control, and the transition to school. Interest, perceived competence, and response inhibition were evaluated as predictors of children's $\left(\mathrm{N}=73, \mathrm{M}_{\mathrm{age}}=6.91\right.$ years $)$ likelihood to demonstrate high persistence on a challenging puzzle task. Results provided evidence that motivational constructs are not sufficient for understanding differences in persistent behavior during this developmental period. Specifically, relations between interest and perceived competence and task persistence were only present for children with moderate to high response inhibition skills. Moreover, gender differences in task persistence emerged, indicating that while interest and perceived competence motivated all students to exhibit persistence, girls were still more likely to demonstrate task persistence than boys. Overall, findings suggest that task persistence in elementary school is a complex behavior that requires both cognitive control skills to support engagement and the motivation to continue engaging as task difficulty increases.

Keywords: task persistence, motivational beliefs, cognitive control, self-regulation, children
\end{abstract}




\section{Associations amongst response inhibition, motivational beliefs, and task persistence in early elementary school}

Task persistence is defined as an adaptive approach to learning characterized by a child's ability to focus, resist distractors, and demonstrate continued effort despite cognitive challenge or difficulty (Berhenke et al., 2011; Vitiello et al., 2011). Evidence suggests that task persistence is an important learning-related behavior, with greater levels of persistence relating to academic gains in domains of science, mathematics, and literacy for students ranging from preschool through middle school (Bustamante et al., 2018; Jozsa \& Morgan, 2014; Li-Grining et al., 2010; Mokrova et al., 2013; Newman et al., 1998). Broadly, children's learning-related behaviors have been associated with student ability to modulate cognitive processes and emotions towards goaldirected behaviors - which is critical for academic success, particularly in early schooling (Berhenke et al., 2011; Blair \& Raver, 2015; Morgan et al., 2019). The ability to inhibit inappropriate responses, hold information in working memory, and control attention - referred to as cognitive control processes - have also been identified as important for engaging in classroom activities that require persistence (Akira Miyake \& Friedman, 2012). Moreover, evidence suggests that the relation between cognitive control and academic learning is mediated by student persistence in early elementary school (Sung \& Wickrama, 2018; Vitiello et al., 2011; Vitiello \& Greenfield, 2017), although these relations have yet to be fully examined (Józsa et al., 2017).

One potentially important and often overlooked factor in the association between cognitive control and persistence is children's motivation. Previous research has relied largely on teacher reports of children's cognitive control and persistence that do not directly capture unobservable aspects of motivation (e.g. interest or perceived competence) that may impact 
willingness to persist on a particular activity or task (Barrett \& Morgan, 2018; Eccles \&

Wigfield, 2002). Furthermore, teacher and parent report measures often conflate persistence with related constructs such as engagement, or cognitive and behavioral regulation more broadly (LiGrining et al., 2010; Sasser et al., 2015).

Task-related motivational beliefs and cognitive control have each been studied independently in relation to persistence (Berhenke et al., 2011; Wigfield et al., 2007). However, to be persistent, it is clear that children need to be both motivated and able to engage in cognitive control. Given that all three constructs have rarely been examined together, relatively little is known about how cognitive control and motivational beliefs interact to support persistent behavior. The transition to elementary school is a particularly interesting developmental period for examining these relations as it is characterized by rapid development of cognitive control skills (McAuley et al., 2011; Montroy et al., 2016; Roebers et al., 2011) and important transitions in children's motivational beliefs (Muenks et al., 2018; Spinath \& Spinath, 2005). In the current study, we employ direct assessments of children's persistence, cognitive control, and motivation to understand the associations amongst them in early elementary school students.

\section{Task Persistence}

Task persistence has been associated with teacher reports of students' academic competencies as well as student social and self-regulation skills (Berhenke et al., 2011; Fantuzzo et al., 2005; Li-Grining et al., 2010). Specifically, ratings of student persistence have been linked to behavioral assessments of cognitive control (Sasser et al., 2015; Sung \& Wickrama, 2018; Vitiello \& Greenfield, 2017), the acquisition of early reading and math skills (Newman et al., 1998; Schmerse, 2020), and achievement trajectories in math and reading across elementary school (Li-Grining et al., 2010). 
Much of the research on persistence is based on global parent or teacher reports of children's engagement in the classroom or with homework materials (Schmerse, 2020; Sung \& Wickrama, 2018; Vitiello et al., 2011; Vitiello \& Greenfield, 2017). However, learning-related behaviors are thought to be context or task-specific (Barrett \& Morgan, 2018; Eccles \& Wigfield, 2002). As such, to narrow in on persistence in specific circumstances, researchers have employed behavioral measures including novel puzzles or trivia games to observe children's approaches to challenge (Smiley \& Dweck, 1994). In these assessments, duration of time spent on task or number of failed attempts serve as measures of task persistence (Berhenke et al., 2011; Chang \& Burns, 2005; Lunkenheimer \& Wang, 2017; Mokrova et al., 2013). Using these methods, researchers have found that preschool children's persistence on a challenging puzzle task predicted behavioral assessment scores (Lunkenheimer \& Wang, 2017) and teacher ratings of self-regulation (Berhenke et al., 2011), as well as performance on standardized measures of math, literacy, and language proficiency (Mokrova et al., 2013). Combined, these finding suggests that duration of persistence is a valid indicator of a child's early adaptive approach to learning and that longer engagement with a challenging, but achievable task benefits acquisition of academic material.

Overall, children's persistence is correlated with academic performance across schooling. Research suggests that while this is true on average, individual children's persistence can fluctuate as a function of context (Ryan \& Deci, 2000) and over time (Jozsa \& Morgan, 2014). Additionally, gender may be an important factor in considering task persistence in early schooling. Indeed, a recent study found that teachers in Israel, Finland, and Holland rate 4-6year-old girls as having greater task orientation (initiation and persistence at a task) and lower task avoidance (showing negative emotions) than their male peers (Brody et al., 2020). This 
finding corroborates previous work indicating that girls in early elementary schools in the United

States are more persistent at puzzle tasks than boys (Binco, 1992; Gilmore et al., 2003).

However, no work to our knowledge has examined cognitive control as a factor of task

persistence in conjunction with the child's task-specific motivational beliefs.

\section{Motivational Beliefs}

Children's motivational beliefs in early childhood can be examined along dimensions of interest (value) and perceived competence (expectation). The Expectancy-Value (E-V) model proposes that individual differences in achievement and achievement-related behaviors, such as engagement or persistence with a novel task, can be explained by beliefs regarding how well an individual believes he/she (a) will perform on an activity and (b) will enjoy or value that activity (Wigfield et al., 2007). In this model, expectancy refers to an individual's expectations for task success based on perceived competence and previous experiences with similar tasks or activities. Value refers to an individual's belief regarding the attainment, utility, relative cost, and interest in an activity. Children have many experiences making choices based on interest early on, particularly with toys in home settings. Thus, interest, rather than attainment, utility, or cost, is thought to be most salient for younger children and the first feature of value to develop (Eccles \& Wigfield, 2002; Jacobs et al., 2002).

A child's previous experiences with success and failure influence their motivational beliefs towards specific tasks and activities, which in turn affects their likelihood of demonstrating learning-related behaviors (Wigfield et al., 2007). Thus, it is expected that children with greater motivational beliefs will be more likely to show higher task persistence. Children who report high interest are expected to demonstrate higher task persistence because they enjoy the activity. Similarly, children who report high perceived competence are expected 
to show greater task persistence because they hold stronger beliefs about their ability to complete the task. However, it is possible that a child's interest or perceived competence may fluctuate during the duration of a task, particularly if they experience task failure. As such, in the current investigation, interest and perceived competence are assessed following task completion, as to indicate overall interest and perception of task competency.

Although in the E-V model task persistence is conceptualized as a product of the interactions between expectancy and value, previous work indicates that young children are overly optimistic about their expectancy for success, reporting high perceived competence that is not related to their actual ability to complete the task (Jacobs et al., 2002; Muenks et al., 2018; Spinath \& Spinath, 2005). Therefore, in early schooling, high perceived competence may instead be reflective of developmental changes in the cognitive control skills that support more accurate performance judgments (van Loon et al., 2017), further suggesting post-task assessment of perceived competence in this age range may be better for assessing factors of task persistence. Thus, here we investigate interest and perceived competence as independent predictors of task persistence rather than interacting constructs, in order to better understand the functionality of motivational beliefs on task persistence as they are developing in early elementary school. Specifically, we examine whether relations between motivational beliefs (interest and perceived competence) and task persistence are conditional upon children's cognitive control abilities that are necessary for engagement with challenging material.

\section{Cognitive Control Skills}

Broadly, cognitive control, often referred to as executive functions, involves the coordination of multiple cognitive subprocesses that help children set, plan, and achieve a taskrelated goal (Friedman \& Miyake, 2017). Although studies have demonstrated associations 
between cognitive control and persistence, more often than not this work has relied on global ratings of children's persistence and cognitive control in the classroom as reported by their teachers (Berhenke et al., 2011; Lunkenheimer \& Wang, 2017; Mokrova et al., 2013; Vitiello et al., 2011). While informative, teacher reports provide limited insight into the dynamic associations between motivational states and children's use of cognitive control skills when they are engaged in specific tasks.

Alternatively, aspects of cognitive control can be assessed with behavioral tasks that are designed to tap into the functions of separable, but related, componential skills including attention shifting, inhibition, and working memory (Friedman \& Miyake, 2017; Miyake et al., 2000; Miyake \& Friedman, 2012). Response inhibition, or the ability to inhibit an inappropriate prepotent response, develops rapidly across early childhood, is thought to relate to broader inhibitory behaviors, and is most associated with children's academic performance during this period in development (Grammer et al., 2014; McClelland et al., 2015; Montroy et al., 2016; Roebers et al., 2011). Response inhibition may be particularly important when children are engaged in challenging tasks in school as children must inhibit the prepotent desire to disengage from the challenge to be persistent. Although response inhibition plays a critical role in the regulation of cognitive and emotional processes in the face of a challenge, little is known about direct associations between response inhibition and task persistence.

A few studies have examined both cognitive control and motivational beliefs in early elementary school (Chang \& Burns, 2005; Kim et al., 2017). However, none have directly focused on behavioral measures of cognitive control and task-specific self-reports of motivational beliefs as contributing factors to task persistence. Concurrent behavioral assessments of cognitive control, motivational beliefs, and task persistence are necessary to 
examine the ways in which cognitive control and motivation work together as children engage in challenging tasks.

\section{Current Study}

The goal of this study is to explore student task persistence in early elementary school. In this investigation, task persistence was assessed as duration of engagement with a challenging puzzle task. Children's interest and perceived competence were assessed through self-reports following the challenging puzzle task. One aspect of cognitive control, response inhibition, was measured as an indicator of children's ability to follow task directions and appropriately suppress a behavioral response. Interest and perceived competence were assessed as factors of task persistence in separate moderation models, in order to investigate if each relation was dependent on response inhibition. This is supported by previous work indicating that interest and perceived competence have opposite relations to neural processes associated with response inhibition in

early elementary school, suggesting that combining all constructs in one model might cloud our initial understanding of the relation between motivation, cognitive control, and task persistence in this age range (Kim et al., 2017).

It was anticipated that interest and perceived competence would be differentially related to task persistence in this early schooling sample. Specifically, when children are still developing the cognitive skills necessary for accurate performance judgments (van Loon et al., 2017), greater perceived competence may reflect an overly optimistic belief about their ability to complete a task and be less related to a child's task persistence. Therefore, it is less likely that a direct relation between perceived competence and task persistence would be observed. In contrast, interest is an aspect of motivation with an earlier developmental trajectory (Jacobs et al., 2002). As a result, we hypothesized that children reporting high interest in the challenging 
puzzle task would demonstrate greater task persistence, reflecting previous experience engaging with activities and toys in their home based on their level of interest. We also expected that girls may be more likely to demonstrate high task persistence than boys, as indicated in previous work (Brody et al., 2020).

Moreover, we anticipated that the relation between motivational beliefs and task persistence would depend on a child's level of response inhibition. It was expected that children with greater response inhibition skills would be more likely to accurately judge a challenging task as difficult, report low perceived competence, and accordingly exhibit low task persistence (Wigfield et al., 2007). Because interest in this age range is thought to be more developed, we anticipated that observed differences in task persistence may reflect differences in self-reports of interest for children with average or above average response inhibition skills.

To explore these hypotheses, we addressed the following research questions:

1. Do self-reports of interest and perceived competence increase the likelihood that children in early elementary school will exhibit greater task persistence?

a. Does gender predict persistence after accounting for differences in motivational beliefs?

2. Are relations between motivational beliefs and task persistence dependent on children's level of response inhibition skills?

\section{Methods}

\section{Participants}

Children from eight kindergarten and primary classrooms (inclusive of Grades 1-2) were invited to participate, yielding an initial sample of 87 children $\left(\mathrm{M}_{\mathrm{age}}=6.94\right.$ years, $\left.\mathrm{N}_{\mathrm{boys}}=33\right)$ recruited across two school years $\left(\mathrm{N}_{\text {Year1 }}=41 ; \mathrm{N}_{\text {Year2 }}=46\right)$ at a university-affiliated, community- 
based, laboratory school in Southern California. Three classrooms were designated as bilingual classrooms, teaching in Spanish and English. All participating children were proficient in and assessed in English. Overall, the socioeconomic composition of participants reflected the population of the school, with most families reporting incomes that would be categorized as middle to upper-middle class. Children's race/ethnicity was also representative of the diversity of the school, with $26.19 \%$ of families identifying as Caucasian, $14.29 \%$ Latino, $5.95 \%$ Asian, 4.76\% African American, $46.41 \%$ as bi- or multi-racial, and $2.37 \%$ as other. Bi and multi-racial children were reported as Latino-Caucasian (11.90\%), African American-Caucasian (5.95\%), African American-Latino-Caucasian (4.76\%), Asian-Caucasian (3.57\%), Latino-Asian (2.38\%), and bi- $(10.71 \%)$ or multiracial other $(7.14 \%)$.

The final sample in the analyses presented include 73 kindergarten $(\mathrm{N}=38)$ and primary (inclusive of Grades 1-2, N=35) students with complete behavioral data for tasks assessing motivation, cognition, and task persistence $\left(\mathrm{M}_{\mathrm{age}}=6.91\right.$ years, $\left.\mathrm{N}_{\mathrm{boys}}=27\right)$. Data from 14 children were not included in the final sample due to issues with task performance and/or technical issues associated with the computerized cognitive control task. Specifically, 10 children did not complete the cognitive control task, including two children with reported diagnoses of neurodevelopmental disorders, and one child that ended the session early due to lack of time. Two children's data were excluded from the final data set for not actively participating in the task, as indexed by $30 \%$ or greater errors of omission. Data from two additional students were lost due to equipment failure. These 14 children did not differ significantly from the included sample on age $(p=.39)$ or on the focal outcome measures of persistence $(p=.30)$, interest $(p=.25)$ or competence $(p=.80)$.

\section{Procedures and Materials}


Children participated in two assessments as a part of a larger study designed to assess their cognitive, motivational, and academic skills. All assessments were conducted with an experimenter in a quiet space within the school. In the first assessment, children completed a challenging puzzle task designed to assess task persistence as well as a puppet interview involving questions regarding motivational processes. As a part of the second assessment, children completed a child-friendly Go/No-Go task to measure response inhibition. In total, assessments lasted 90 minutes, and the two assessments were completed within an average of 47 days. All recruitment and study procedures were approved by both the supporting university's institutional review board and the IRB of the school from which children were recruited.

\section{Persistence Task}

The Challenging Puzzle Persistence Task was designed to measure young children’s achievement goal orientations (Kim et al., 2017; Smiley \& Dweck, 1994). Stimuli for the puzzle task were selected to be similar to toys and games that children might be familiar with, and involved manipulating colored blocks of various shapes and sizes. In this task, children were shown a card with a design and asked to arrange the blocks to match the design on the card. If the child successfully completed the first design in four minutes or less, a second, more challenging design was provided. The task continued until the child attempted a design that he or she was unable to successfully complete in four minutes (maximum of four puzzles). When the child was unable to solve a puzzle (either the child 'gave up' or four minutes passed), the experimenter ended the task. Persistence in this task was measured as the duration of time the child attempted the 'failed' puzzle. Maximum time allotted for attempting a puzzle was 4 minutes (240 s) in line with previous research (Kim et al., 2017). Children were not told they had a time limit to attempt the puzzle. 


\section{Assessment of Student Motivation}

Directly following the puzzle task, the experimenter administered a puppet interview to assess the child's interest and perceived competence for the puzzle task. This eight-item measure was adapted from the Puppet Interview Scales of Competence in and Enjoyment of Science (Mantzicopoulos et al., 2008), in which children were presented with puppets that "spoke" to the child. One puppet said a positive statement (i.e. "I like doing puzzles like this one.”) and the other said a negative statement (i.e. "I don't like puzzles like this one."). The experimenter then asked the child to identify which puppet thought the same as them and directed the child to point to the matching puppet. Children responded to four dichotomous statements that captured perceived competence (Puzzles like this one are easy/hard, I know/don't know how to do puzzles, I can/can't do puzzles, I'm good/not so good at puzzles) and four dichotomous statements that captured interest (I like/don't like doing puzzles like this one, I have/don't have fun doing puzzles, I want/don't want to know more about puzzles, I feel/don't feel happy when I am doing puzzles). Prior to assessment of perceived competence and interest, children were introduced to two randomly chosen animal puppets (tiger, monkey, giraffe, zebra) as Alex and Taylor (gender-matched to the child) and presented with two 'test' statements about recess and pizza to check for understanding and puppet preference. Positive and negative statements were balanced between the puppets. Scoring for both the interest and perceived competence subscales range from 0 to 4 and were calculated as a summation score with negative statements scored as 0 and positive statements scored as 1 .

\section{Go/No-Go Task}

Children completed a child-friendly Go/No-Go task (Grammer et al., 2014) presented on a laptop using E-Prime 2.0 (Psychology Software Tools, 2010). Children that participated in the 
first wave of data collection completed a Go/No-Go with a "zoo" storyline. A change in task stimuli was made for wave 2 of testing to reduce redundancy and interference between this task and one that followed it in our broader assessment battery. Both versions of the task were identical in all parameters that have been shown to be associated with measurement of response inhibition (e.g., stimulus duration, ratio of go/no-go trials), varying only in the storyline that introduced the task and in the visual stimuli. All children in wave 2 completed the Go/No-Go with an "underwater" storyline. At the start of the task, children were given directions to the task embedded in either a "zoo" (wave 1) or "underwater" (wave 2) storyline. In each version, children were told that they were playing a game in which their goal was to help either a zookeeper put animals back in their cages or scuba diver take photos of sea creatures. They were then informed that three of the animals (zoo) or fish (underwater), were helping. Children were asked to press a button as quickly as they could every time they saw a picture of an animal or sea creature (Go Trials) but to inhibit their response each time they saw a helper (No-Go trials).

The task began with a brief practice block consisting of 12 trials, 9 with Go images and 3 with No-Go images. The children then completed 8 blocks of the task, each with 40 trials (each including 10 images of the helpers and 30 novel pictures), for a total of 320 trials. Each trial started with the presentation of a fixation cross for $300 \mathrm{~ms}$, then an image of an animal (the stimulus) for $500 \mathrm{~ms}$, followed by a blank black screen for $500 \mathrm{~ms}$. Responses were registered during stimulus presentation as well as during the blank screen. All images were of the same size and were selected carefully so that the stimuli were easily identifiable from the background but were not particularly salient for other reasons. This was done in order to prevent children from being drawn to a particular stimulus because of the image background or other peripheral features. 
Children made responses on a standard game controller (Logitech Dual Action Gamepad USB). Both speed and accuracy were emphasized; participants were instructed to press the button as fast as possible, with regular reminders given not to press the button for No-Go trials. To sustain enthusiasm and task engagement, children were provided with short breaks, as necessary.

Trials in which children responded in under $50 \mathrm{~ms}$ of Go/No-go stimuli were excluded from all analyses, consistent with methods used in the original and subsequent implementations of the task (Grammer et al., 2014). Additionally, participants who exhibited an overall accuracy rate below $70 \%$ on Go trials were also excluded. For the purposes of the current investigation, we will be examining one behavioral performance variable of interest, the percentage of errors of commission (incorrect No-Go trials). No-Go trials are described as more difficult than Go trials, as they require response inhibition skills and appeared less frequently in our paradigm. A lower percentage of commission errors reflects higher levels of response inhibition.

\section{Statistical Approach}

Preliminary descriptive analyses were run for all variables of interest (see Table 1). As expected in this age range, both persistence and motivational beliefs were high and negatively skewed, indicating that dichotomous variables would be most appropriate for subsequent analyses to understand differences in children with atypical (low) task persistence, interest, and perceived competence. Task persistence was recoded as 0 , "child initiated" cessation of task (less than 240s) operationalized as low persistence $(n=23)$ and as 1 , "experimenter initiated" cessation of task (maximum allotted time of 240s) operationalized as high persistence $(n=50)$. Measures of motivation, interest and perceived competence, were recoded such that 0 signaled 
low motivational beliefs (sum score of 0,1 , or 2 ) and 1 indicated high motivational beliefs (sum score of 3 or 4). Descriptive information on dichotomized groups are presented in Table 2.

\section{Table 1}

Descriptive Information

\begin{tabular}{lllll}
\hline Variable & $M$ & $S D$ & \%High & \%Low \\
\cline { 2 - 5 } Duration of Task Persistence (s) & 199.14 & 69.32 & 68.49 & 31.51 \\
Interest & 2.74 & 1.30 & 63.01 & 36.99 \\
Perceived Competence & 2.86 & 0.98 & 72.60 & 27.40 \\
Percent Errors of Commission & 42.50 & 16.37 & - & - \\
\hline
\end{tabular}

To address the main research questions, two logistic regressions using the PROCESS macro for SPSS (Hayes, 2017) were conducted to examine the predicted probability that a student would demonstrate high task persistence. Perceived competence and interest were examined in separate models, as they have been described as independent motivational constructs in the age range of the current sample (Jacobs et al., 2002) and may relate differentially to task persistence on a challenging puzzle game. To assess whether response inhibition skills uniquely accounted for additional variance in children's likelihood of demonstrating persistence, a mean-centered measure of percent errors of commission was added to both models as a continuous predictor. In addition, to determine whether response inhibition moderated the relation between student interest or perceived competence and task persistence, interaction terms between percent errors of commission (mean centered) and interest or perceived competence were also explored. This allowed us to examine the effect of interest and perceived competence on likelihood of task persistence across different levels of response inhibition. Bootstrap analysis $(n=1000)$ to examine stability of effects was employed. The role of potential covariates, including age and gender (Anderson, 2002; Corpus \& Lepper, 2007; Ready et al., 2016), was assessed using bivariate Pearson correlations, and included in subsequent 
analyses when statistically significant $(\alpha=.05)$, as indicated below. IBM SPSS 22.0 was utilized for all analyses.

\section{Results}

Based on preliminary analyses, only gender was included as a covariate in the logistic regression models (see Table 3). Statistical significance was determined at an alpha level of .05 for both model and coefficient significance, and effect sizes are reported using the Cox and Snell RSquare value. Odds ratios were calculated for each predictor using the formula $\mathrm{e}^{\wedge}{ }_{\mathrm{x}}$. For ease of interpretation throughout the text, student likelihood of demonstrating high task persistence is reported as the difference in probability scores between students with differing characteristics (interest, perceived competence, response inhibition, etc.), using the appropriate summation of $\beta$ values. Probabilities were calculated using the formula $\mathrm{e}^{\wedge \log \text { odds }} / 1+\mathrm{e}^{\wedge \log \text { odds }}$.

\section{Interest Model}

Results for the model predicting task persistence as a function of response inhibition and self-reported interest can be found in Table 4. Interest $(\beta=1.56, p=.010)$ and the interaction term between interest and errors of commission $(\beta=-0.11, p=.004)$ were the only statistically significant coefficients in the model $\left(\chi^{2}(4,73)=18.29, p=.001, R^{2}=.22\right)$. Results indicate that the odds that children with high interest will exhibit high task persistence is expected to be 4.76 times greater than children with low interest. Specifically, boys with average response inhibition skills are expected to be $37.02 \%$ more likely to demonstrate high task persistence if they have high interest than if they have low interest. Similarly, girls with average response inhibition skills are predicted to be $28.75 \%$ more likely to demonstrate high persistence than girls with the same level of response inhibition skills but low interest. 


\section{Table 2}

Descriptive Information by Dichotomized Groupings

\begin{tabular}{|c|c|c|c|c|c|c|c|c|c|c|}
\hline \multicolumn{6}{|c|}{ Low } & \multicolumn{5}{|c|}{ High } \\
\hline & Age & Boys & Error & Low I & Low $\mathrm{C}$ & Age & Boys & Error & Low I & Low $\mathrm{C}$ \\
\hline Task Persist (P) & $6.71(0.95)$ & 44.44 & $43.34(16.63)$ & 19.18 & 10.96 & $6.99(1.01)$ & 55.56 & $42.11(16.40)$ & 17.81 & 16.44 \\
\hline Interest (I) & $8.82(1.05)$ & 51.85 & $44.83(18.75)$ & - & - & $6.94(0.96)$ & 48.15 & $41.12(14.84)$ & - & - \\
\hline Competence (C) & $6.83(0.96)$ & 22.22 & $48.95(19.05)$ & - & - & $6.93(1.01)$ & 77.78 & $40.06(14.70)$ & - & - \\
\hline
\end{tabular}

Note. Percent errors of omission is indicated as Error. For continuous measures (age, error) mean

is presented with standard deviations in parentheses. "Boys" indicates percent of boys in each

group. Low I reflect the percent of the sample with low interest and Low C indicates the percent

of sample with low competence in each group. 


\section{Table 3}

Correlations between Study Variables

\begin{tabular}{lllllll}
\hline & 1. & 2. & 3. & 4. & 5. & 6. \\
1. Age & 1 & & & & & \\
2. Female & -.159 & 1 & & & & \\
3. Error & .025 & --.037 & 1 & & & \\
4. Interest & .061 & $.236^{*}$ & -.110 & 1 & 1 & \\
5. Competence & .043 & -.089 & $-.244^{*}$ & $.299^{+}$ & .112 & 1 \\
6. Persistence & .129 & $.213^{+}$ & -.035 & $.336^{* *}$ & .12 \\
\hline
\end{tabular}

Note. Percent Errors of Omission is indicated as Error. Interest, Competence, and Persist are dichotomous variables of 0 and 1 . Gender is coded 0 for male, 1 for female. ${ }^{+} \mathrm{p}<.10, * \mathrm{p}<.05, * * \mathrm{p}<.01, * * * \mathrm{p}<.001$.

Next, we probed the moderator and found that the relation between interest and task persistence was only significant for children with average to high response inhibition skills (JohnsonNeyman value=3.66, effect=1.15, LLCI=0.00, ULCI=2.30; see Figure 1), approximately $60.27 \%$ of the current sample. For children with average to high response inhibition skills, the model predicts that the positive effect of interest on task persistence is expected to increase by 0.11 for every one percent fewer errors of commission. For $39.73 \%$ of the sample, with lower response inhibition skills, the relation between interest and task persistence was non-significant (see Figure 2). 


\section{Table 4}

Interest, Response Inhibition, and Task Persistence

\begin{tabular}{lllllll}
\hline & $\mathrm{B}$ & Std. Error $^{\mathrm{a}}$ & $P^{\mathrm{a}}$ & LLCI $^{\mathrm{a}}$ & ULCI $^{\mathrm{a}}$ & Odds Ratio \\
Interest & 1.56 & 5.79 & .010 & 0.29 & 3.67 & 4.76 \\
Errors & 0.04 & 0.24 & .052 & -0.01 & 0.12 & 1.04 \\
Interest X Errors & -0.11 & 0.24 & .004 & -0.25 & -0.04 & 0.89 \\
Female & 0.99 & 0.75 & .106 & -0.29 & 2.64 & 2.69 \\
Constant & -0.66 & 5.75 & .215 & -2.16 & 0.48 & 0.52 \\
\hline
\end{tabular}

Note. Percent Errors of Omission is indicated as Errors. Interest is dichotomous variable of 0 and

1 , thus interaction variable is only indicating children in high intrinsic group. Errors was mean centered for analyses and thus a one-unit increase is one-unit above the mean. ${ }^{\text {a Bootstrap }}$ analysis $(n=1000)$.

\section{Figure 1}

Response Inhibition Moderates Relation between Interest and Task Persistence

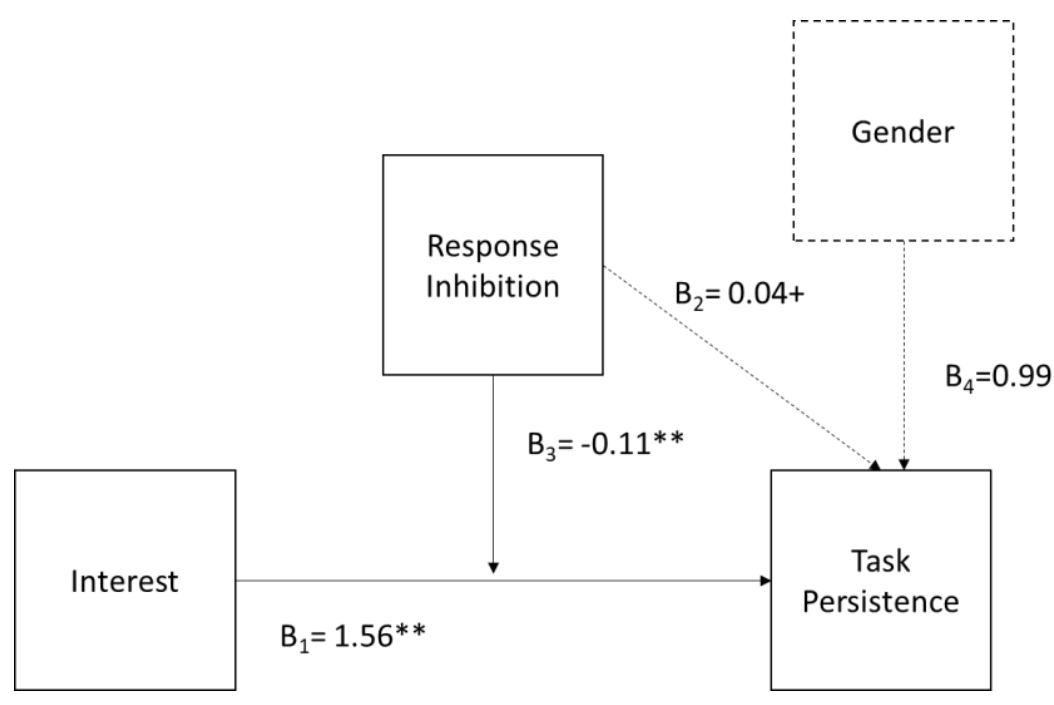


$+p<.10, * p<.05, * * p<.01, * * * p<.001$.

\section{Figure 2}

Effect of Interest on Task Persistence across Levels of Response Inhibition

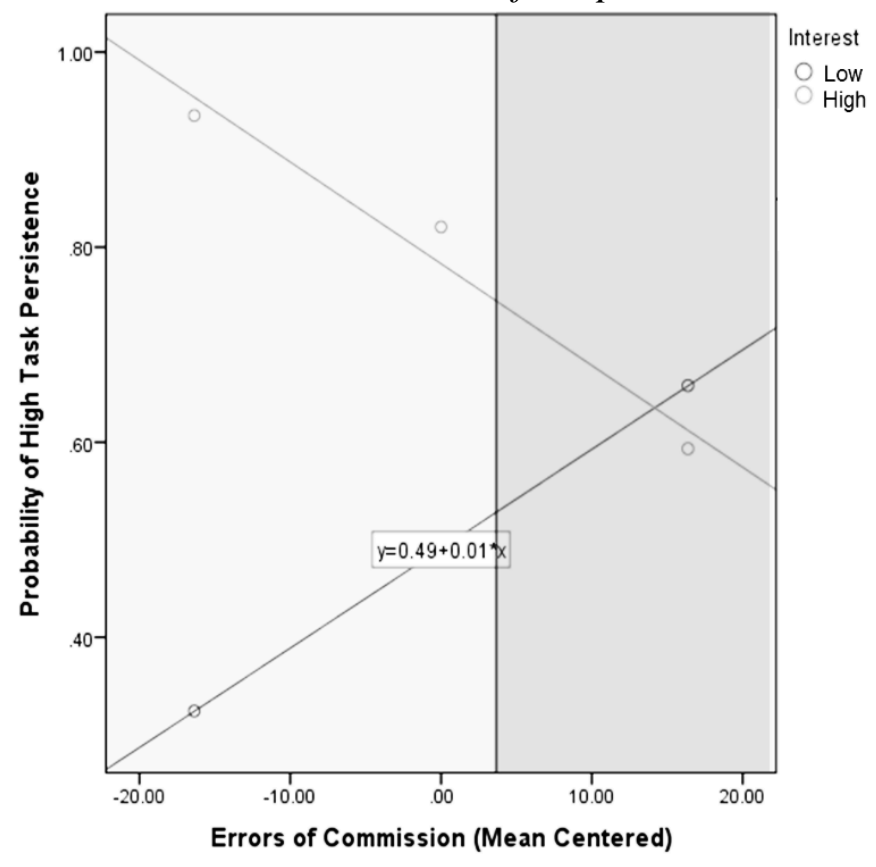

Note. Plot points represent average and +/- 1SD performance on errors of commission. Vertical line indicates Johnson-Neyman point. Relation between interest and task persistence is only significant to the left of the line.

\section{Perceived Competence Model}

Table 5 displays results for the model predicting task persistence as a function of response inhibition and self-reported perceived competence $\left(\chi^{2}(4,73)=9.90, p=.042, R^{2}=.13\right)$. Gender $(\beta=1.12, p=.045)$ and the interaction term between percent errors of commission and competence $(\beta=-0.08, p=.012)$ were the only statistically significant predictors in the model. Overall, the odds that a girl will demonstrate high task persistence is predicted to be 3.05 times higher than a boy's, regardless of perceived competence or errors of commission. Specifically, for children with average response inhibition skills and low competence, a girl is expected to be 
$27.18 \%$ more likely to show high persistence than a boy. Similarly, a girl with average response inhibition skills and reported high competence is predicted to be $23.20 \%$ more likely to exhibit high task persistence than a boy with the same level of perceived competence and response inhibition skills.

However, findings showed that the relation between perceived competence and task persistence was only significant for children with high response inhibition skills (JohnsonNeyman value $=-5.61$, effect $=1.34, \mathrm{LLCI}=0.00, \mathrm{ULCI}=2.67$ ), only $36.99 \%$ of the current sample. For each percent fewer errors, it is expected that the relation between perceived competence and task persistence will increase by 0.08 if gender is constant. For $63.01 \%$ of the sample with low to average response inhibition skills, the relation between perceived competence and task persistence was non-significant (see Figure 4).

Table 5

Competence, Response Inhibition, and Task Persistence

\begin{tabular}{|c|c|c|c|c|c|c|}
\hline & B & Std. Error ${ }^{a}$ & $p^{\mathrm{a}}$ & $\mathrm{LLCI}^{\mathrm{a}}$ & $\mathrm{ULCI}^{\mathrm{a}}$ & $\begin{array}{l}\text { Odds } \\
\text { Ratio }\end{array}$ \\
\hline Competence & 0.88 & 14.49 & .135 & -1.29 & 2.46 & 2.42 \\
\hline Errors & 0.05 & 1.28 & .060 & -0.02 & 0.27 & 1.05 \\
\hline $\begin{array}{l}\text { Competence } \\
\text { X Errors }\end{array}$ & -0.08 & 1.28 & .012 & -0.30 & -0.01 & 0.92 \\
\hline Female & 1.12 & 0.64 & .045 & 0.02 & 2.55 & 3.05 \\
\hline Constant & -0.60 & 14.49 & .334 & -2.20 & 1.54 & 0.55 \\
\hline
\end{tabular}

Note: Percent Errors of Omission is indicated as Errors. Competence is dichotomous variable of

0 and 1 , thus interaction variable is only indicating children in high competence group. Errors were mean centered for analyses and thus a one-unit increase is one-unit above the mean.

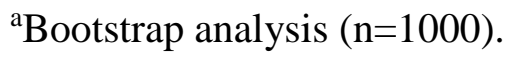




\section{Figure 3}

Response Inhibition Moderates Relation between Perceived Competence and Task Persistence

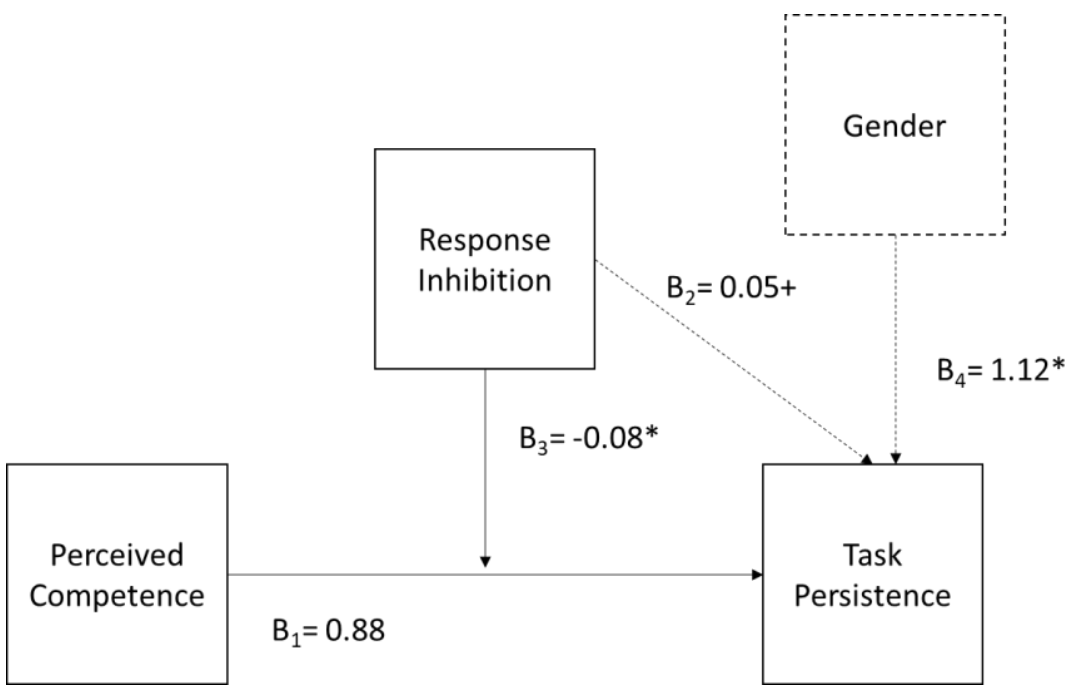

$+p<.10, * p<.05, * * p<.01, * * * p<.001$. 


\section{Figure 4}

Effect of Perceived Competence on Task Persistence across Levels of Response Inhibition

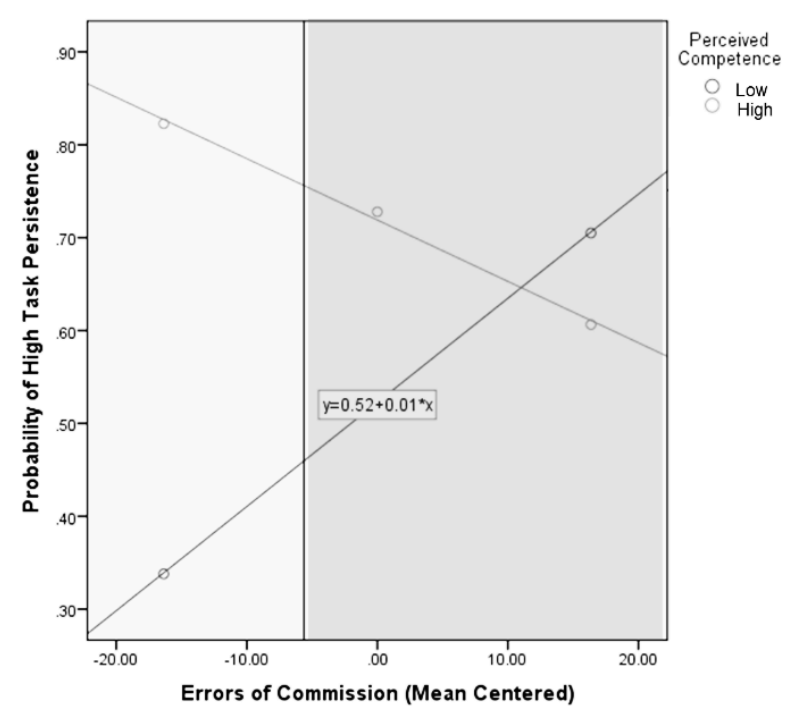

Note. Plot points represent average and +/- 1SD performance on errors of commission. Vertical line indicates Johnson-Neyman point. Relation between perceived competence and task persistence is only significant to the left of the line.

\section{Discussion}

Children's task persistence becomes increasingly important as they enter school and encounter new learning challenges (Li-Grining et al., 2010). To be persistent, children must have the cognitive control skills necessary for sustaining attention and inhibiting inappropriate responses, and they must be motivated to do so. Relatively little is known about how cognitive control and motivation contribute to individual differences in young children's task persistence during this important period in development. Further, differences in the developmental trajectories of motivational beliefs suggest that interest may be more salient than perceived competence in this age range. Focusing on predictors of response inhibition skills and 
motivational beliefs on student task persistence on a challenging puzzle game, the current study examined how these factors contributed to task persistence in young children. Findings indicated that response inhibition skills moderated the relation between motivational beliefs and task persistence, such that children with low response inhibition skills did not show a relation between belief (interest or perceived competence) and task persistence. In the context of this type of task, this pattern of associations makes sense. Children who struggle to inhibit inappropriate responses - including the desire to do something easier in the face of a challenging task - are less likely to be persistent even if they are interested and feel that they might be good at it in general. This might be of even greater importance when children are young, and still developing inhibition skills. These data were sampled from a laboratory school, where families were racially diverse and largely reported their income to be in the range of middle to upper-middle class. Accordingly, appropriate reservations for generalizability should be considered. Previous evidence indicates that school type (public, rural, urban, private) may be relevant when considering gender differences in persistence (Binco, 1992). As such, we acknowledge that future research with larger socioeconomic variation and in differing school contexts would be highly beneficial to replicate these initial findings.

\section{Motivational Predictors}

Results from these analyses revealed that when children had the same level of response inhibition skills, having high interest increased a child's probability of showing high task persistence compared to children with low interest for the task. Consistent with previous work, children in our sample rated themselves as high on both interest and perceived competence. Children's interest is particularly salient in this age window. As described by Jacob and colleagues (2002), interest is the first motivational belief to be uniquely distinguishable in child 
self-reports and reports of interest become increasingly stable around age 7 . Thus, it is likely that children's self-reports of interest in puzzles were accurate predictors of their willingness to engage with a challenging puzzle. However, we did not find a direct relation between perceived competence and student task persistence in our study. It is possible that this pattern of results was partly due to the way in which perceived competence was measured: students reported motivational beliefs after completing the puzzle game. Thus, our perceived competence measure may also have captured children's performance evaluations. As such, this post-task assessment of perceived competence likely represented a child's belief about their task competency as well as a child's general perceived ability for puzzle tasks. These types of evaluations are also challenging for young children who, in addition to espousing high levels of motivational beliefs, often have overly positive appraisals of their performance (Krebs \& Roebers, 2010; van Loon et al., 2017). Perceived competence in our sample likely did not reflect accurate judgments of performance, particularly for students with lower cognitive control skills.

\section{Intersection between Cognitive Control and Motivational Beliefs}

In contrast to children's interest, no direct effect of response inhibition was observed on children's persistence. However, the interaction between response inhibition skills and both measures of student motivational beliefs was found to have a significant effect on likelihood of persistence. Relations between motivational beliefs and task persistence were dependent upon children's level of response inhibition.

Interest significantly increased the likelihood that children would demonstrate high task persistence for children with average or high response inhibition skills. However, interest was not related to task persistence for children with low response inhibition skills. The effect of interest increased across levels of response inhibition, such that children with the fewest errors of 
commission had the greatest effect of interest on task persistence. Therefore, we hypothesize that when children have adequate cognitive control skills within which to engage in a challenging task, a greater level of interest will predict greater persistence.

Further, our findings indicated that in this age range, perceived competence may be dependent on a child's ability to accurately judge their performance (van Loon et al., 2017). Specifically, we found that only children with higher than average performance on the cognitive control task showed a relation between perceived competence and task persistence. Notably, this was representative of roughly one-third of the current sample. This pattern of findings may be explained by individual differences in a key element of cognitive control, error monitoring. Across development, children become increasingly able to monitor when they have made mistakes, and this increased error awareness is thought to contribute to changes in behavior during tasks requiring response inhibition, such as the Go/No-Go used in the current study (Buzzell et al., 2017; Torpey et al., 2012). This same awareness has implications for children's awareness of their capabilities on a task. With this in mind, we hypothesize that young children with higher response inhibition skills are also able to accurately perceive their competence for a task and exhibit a level of task persistence that aligns with their expectancy for success.

Therefore, to understand the links between motivation and learning-related behaviors like persistence in early schooling, it is also important to factor in children's cognitive control. Indeed, our data indicated that the intersection between cognition and motivation may be particularly important for understanding factors of task persistence.

From a developmental perspective, this pattern of findings is intriguing. For many children, the transition into elementary school represents increased encounters with academic activities that are challenging and frustrating. Likely as a result of these experiences, by middle 
childhood their motivational beliefs start becoming more realistic (Jacobs et al., 2002), whereas persistence tends to decrease (Jozsa \& Morgan, 2014). Therefore, future work examining developmental changes in the pattern of associations between motivation, cognitive control, and persistence across the elementary school years would provide a foundation for understanding the factors that promote persistence for individual learners.

\section{Gender Differences}

Another finding that emerged from these results involved the role of gender. In this study, girls were found to be more likely to demonstrate high task persistence than boys. This finding is consistent with reports indicating that that girls between 4-8 often outperform boys in behavioral regulation (Hosseini-Kamkar \& Morton, 2014; Montroy et al., 2016) and have higher ratings of task orientation (Brody et al., 2020). Notably, we did not find any gender differences in the response inhibition measure in our sample, indicating that this effect was not due to gender differences in cognitive control skills. The implications of these early differences in persistence have the potential to go beyond puzzle completion. Indeed, Ready and colleagues (Ready et al., 2016) found that differences in persistence explained part of the gap observed between girls and boys in kindergarten literacy skills.

It is also possible that girls are more attuned to social expectancies than young boys, which could directly impact the persistent behavior of girls relative to boys in the context of a research experiment. Assessments for this study were conducted by an experimenter, who was interacting with participating children throughout the puzzle game. In this study, all experimenters $(\mathrm{N}=5)$ were young-adult females, ages 20-25. Differences in gender socialization may be influencing children's performance, such that teachers reward girls for effort and compliance and boys for achievement and independence (Corpus \& Lepper, 2007). Thus, it is 
possible that the presence of a same-gender adult in the context of the assessment elicited greater levels of persistent behavior from girls. However, further work is needed to test this hypothesis.

While gender played a significant role in the perceived competence model, in contrast the effect of gender on interest was only observed at trend. This suggests that when children's interest is high, other factors associated with gender socialization have less of an impact on persistence. Although sample size limitations prevented us from further investigating interactions between gender and motivational beliefs, understanding these associations in middle childhood when motivational beliefs are generally high for both boys and girls - and later developmental changes in these associations as children transition into adolescence, are important next steps in this line of work.

\section{Future Directions \& Conclusions}

Positive approaches to learning, such as task persistence, are important for the acquisition of early math and reading skills and overall school success. Approaches to learning can be operationalized as a multidimensional construct, that is reflective of student self-regulatory skills and motivational beliefs towards task interest and expectancy for success. From a motivational perspective, the E-V model proposes that task persistence is influenced by both a child's expectancy for success and intrinsic interest in the task at hand (Eccles \& Wigfield, 2002). However, in early elementary school motivational beliefs are generally high and overly optimistic, as children have yet to develop realistic expectations of their abilities (Jacobs et al., 2002; Muenks et al., 2018). Our data indicate that even if children are quite motivated, considering other factors such as cognitive control - or skills that are foundational for helping children orient their attention in the service of a learning goal - may provide a more comprehensive understanding of individual differences in persistent behavior. 
To date, studies linking children's cognitive control processes to task persistence have relied on teacher reports of broad classroom behaviors such as general attention and engagement to characterize these skills (Berhenke et al., 2011; Li-Grining et al., 2010; Lunkenheimer \& Wang, 2017; Vitiello et al., 2011; Vitiello \& Greenfield, 2017). This study is one of the first to behaviorally assess children on both task persistence and cognitive control. A further contribution of this investigation involves focusing on relations between children's cognitive skills, motivational beliefs, and persistent behaviors as these skills are emerging in early elementary school.

There are a number of key developmental questions emerging from these results. In the current project, persistence was assessed on a challenging puzzle. Although challenging, this type of task poses different cognitive demands than a difficult mathematics problem or literacy activity, particularly for young students acquiring academic skills. Additionally, motivation is thought to be domain-specific and therefore, task-specific motivational beliefs may be more indicative of children's willingness to persist on academic tasks (Barrett \& Morgan, 2018). Given the potential relevance of these results for understanding children's persistence in academic settings, an important next step involves exploring the relations between response inhibition, domain-specific motivational beliefs, persistence, and learning should be explored. It would also be interesting to see how these patterns of association change as children's reports of motivation become attuned as a function of experience in school over time.

Overall, the current study provides evidence that response inhibition skills are critical for children to engage and persist during a task even if they are reporting high interest or perceived competence. Additionally, findings indicate that girls may be more likely to demonstrate task persistence than boys regardless of whether they report low or high motivational beliefs. Yet, for 
both boys and girls, greater response inhibition skills increased the relation between motivational beliefs and task persistence. Because we did not find any gender differences in our measure of response inhibition, we expect socialization practices are related to this pattern of findings. However, further work will need to be done to investigate mechanisms supporting the effect of gender on task persistence. These results also highlight the important role response inhibition plays in the links between motivation and task persistence, suggesting that cognitive control skills should be considered in motivational models of learning-related behaviors when applied to young children. 


\section{References}

Anderson, P. (2002). Assessment and development of executive function (EF) during childhood. Child Neuropsychology, 8(2), 71-82.

Barrett, K. C., \& Morgan, G. A. (2018). Chapter One - Mastery Motivation: Retrospect, Present, and Future Directions. In A. J. Elliot (Ed.), Advances in Motivation Science (Vol. 5, pp. 1-39). Elsevier. https://doi.org/10.1016/bs.adms.2018.01.002

Berhenke, A., Miller, A. L., Brown, E., Seifer, R., \& Dickstein, S. (2011). Observed emotional and behavioral indicators of motivation predict school readiness in Head Start graduates. Early Childhood Research Quarterly, 26(4), 430-441.

https://doi.org/10.1016/j.ecresq.2011.04.001

Binco, P. M. A. (1992). A cross-cultural study of task persistence of young children in Japan and the United States. Journal of Cross-Cultural Psychology, 23(3), 407-415. https://doi.org/10.1177/0022022192233010

Blair, C., \& Raver, C. C. (2015). School readiness and self-regulation: A Developmental psychobiological approach. Annual Review of Psychology, 66(1), 711-731. https://doi.org/10.1146/annurev-psych-010814-015221

Brody, D. L., Scheiner, E. Y., Ari, M. D. B., Tzadok, Y., Aalsvoort, G. M. van der, \& Lepola, J. (2020). Measuring motivation in preschool children: A comparison of Israeli, Dutch and Finnish children. Early Child Development and Care, 190(2), 150-160. https://doi.org/10.1080/03004430.2018.1459593

Bustamante, A. S., White, L. J., \& Greenfield, D. B. (2018). Approaches to learning and science education in Head Start: Examining bidirectionality. Early Childhood Research Quarterly, 44, 34-42. https://doi.org/10.1016/j.ecresq.2018.02.013 
Buzzell, G. A., Richards, J. E., White, L. K., Barker, T. V., Pine, D. S., \& Fox, N. A. (2017). Development of the error-monitoring system from ages 9-35: Unique insight provided by MRI-constrained source localization of EEG. NeuroImage, 157, 13-26. https://doi.org/10.1016/j.neuroimage.2017.05.045

Chang, F., \& Burns, B. M. (2005). Attention in preschoolers: Associations with effortful control and motivation. Child Development, 76(1), 247-263. https://doi.org/10.1111/j.14678624.2005.00842.x

Corpus, J. H., \& Lepper, M. R. (2007). The effects of person versus performance praise on children's motivation: gender and age as moderating factors. Educational Psychology, 27(4), 487-508. https://doi.org/10.1080/01443410601159852

Eccles, J. S., \& Wigfield, A. (2002). Motivational beliefs, values, and goals. Annual Review of Psychology, 53(1), 109-132. https://doi.org/10.1146/annurev.psych.53.100901.135153

Fantuzzo, J. W., Bulotsky-Shearer, R., Fusco, R. A., \& McWayne, C. (2005). An investigation of preschool classroom behavioral adjustment problems and social-emotional school readiness competencies. Early Childhood Research Quarterly, 20(3), 259-275. https://doi.org/10.1016/j.ecresq.2005.07.001

Friedman, N. P., \& Miyake, A. (2017). Unity and diversity of executive functions: Individual differences as a window on cognitive structure. Cortex; a Journal Devoted to the Study of the Nervous System and Behavior, 86, 186-204. https://doi.org/10.1016/j.cortex.2016.04.023

Gilmore, L., Cuskelly, M., \& Purdie, N. (2003). Mastery motivation: Stability and predictive validity from ages two to eight. Early Education and Development, 14(4), 411-424. http://dx.doi.org/10.1207/s15566935eed1404_2 
Grammer, J. K., Carrasco, M., Gehring, W. J., \& Morrison, F. J. (2014). Age-related changes in error processing in young children: A school-based investigation. Developmental Cognitive Neuroscience, 9, 93-105. https://doi.org/10.1016/j.dcn.2014.02.001

Hayes, A. (2017). Introduction to Mediation, Moderation, and Conditional Process Analysis: Second Edition: A Regression-Based Approach. Guilford Press.

Hosseini-Kamkar, N., \& Morton, J. B. (2014). Sex differences in self-regulation: An evolutionary perspective. Frontiers in Neuroscience, 8. https://doi.org/10.3389/fnins.2014.00233

Jacobs, J. E., Lanza, S., Osgood, D. W., Eccles, J. S., \& Wigfield, A. (2002). Changes in children's self-competence and values: Gender and domain differences across grades one through twelve. Child Development, 73(2), 509-527. https://doi.org/10.1111/14678624.00421

Józsa, K., Barrett, K. C., \& Morgan, G. A. (2017). Game-Like tablet assessment of approaches to learning: Assessing mastery motivation and executive functions. Electronic Journal of Research in Educational Psychology, 15(3), 665-695. https://doi.org/10.14204/ejrep.43.17026

Jozsa, K., \& Morgan, G. A. (2014). Developmental changes in cognitive persistence and academic achievement between grade 4 and grade 8. European Journal of Psychology of Education, 29(3), 521-535. https://doi.org/10.1007/s10212-014-0211-z

Kim, M. H., Marulis, L. M., Grammer, J. K., Morrison, F. J., \& Gehring, W. J. (2017). Motivational processes from expectancy-value theory are associated with variability in the error positivity in young children. Journal of Experimental Child Psychology, 155, 32-47. https://doi.org/10.1016/j.jecp.2016.10.010 
Krebs, S. S., \& Roebers, C. M. (2010). Children's strategic regulation, metacognitive monitoring, and control processes during test taking. The British Journal of Educational Psychology, 80(Pt 3), 325-340. https://doi.org/10.1348/000709910X485719

Li-Grining, C. P., Votruba-Drzal, E., Maldonado-Carreño, C., \& Haas, K. (2010). Children's early approaches to learning and academic trajectories through fifth grade. Developmental Psychology, 46(5), 1062-1077. https://doi.org/10.1037/a0020066

Lunkenheimer, E., \& Wang, J. (2017). It's OK to fail: Individual and dyadic regulatory antecedents of mastery motivation in preschool. Journal of Child and Family Studies, 26(5), 1481-1490. https://doi.org/10.1007/s10826-016-0633-0

Mantzicopoulos, P., Patrick, H., \& Samarapungavan, A. (2008). Young children's motivational beliefs about learning science. Early Childhood Research Quarterly, 23(3), 378-394. https://doi.org/10.1016/j.ecresq.2008.04.001

McAuley, T., Christ, S. E., \& White, D. A. (2011). Mapping the development of response inhibition in young children using a modified day-night task. Developmental Neuropsychology, 36(5), 539-551. https://doi.org/10.1080/87565641.2010.549871

McClelland, M. M., Geldhof, G. J., Cameron, C. E., \& Wanless, S. B. (2015). Development and Self-Regulation. In Handbook of Child Psychology and Developmental Science (pp. 143). American Cancer Society. https://doi.org/10.1002/9781118963418.childpsy114

Miyake, A., Friedman, N. P., Emerson, M. J., Witzki, A. H., Howerter, A., \& Wager, T. D. (2000). The unity and diversity of executive functions and their contributions to complex "Frontal Lobe" tasks: A latent variable analysis. Cognitive Psychology, 41(1), 49-100. https://doi.org/10.1006/cogp.1999.0734 
Miyake, A., \& Friedman, N. P. (2012). The nature and organization of individual differences in executive functions: Four general conclusions. Current Directions in Psychological Science, 21(1), 8-14. https://doi.org/10.1177/0963721411429458

Mokrova, I. L., O’Brien, M., Calkins, S. D., Leerkes, E. M., \& Marcovitch, S. (2013). The role of persistence at preschool age in academic skills at kindergarten. European Journal of Psychology of Education, 28(4), 1495-1503. https://doi.org/10.1007/s10212-013-0177-2

Montroy, J. J., Bowles, R. P., Skibbe, L. E., McClelland, M. M., \& Morrison, F. J. (2016). The development of self-regulation across early childhood. Developmental Psychology, 52(11), 1744-1762. https://doi.org/10.1037/dev0000159

Morgan, P. L., Farkas, G., Hillemeier, M. M., Pun, W. H., \& Maczuga, S. (2019). Kindergarten children's executive functions predict their second-grade academic achievement and behavior. Child Development, 90(5), 1802-1816. https://doi.org/10.1111/cdev.13095

Muenks, K., Wigfield, A., \& Eccles, J. S. (2018). I can do this! The development and calibration of children's expectations for success and competence beliefs. Developmental Review, 48, 24-39. https://doi.org/10.1016/j.dr.2018.04.001

Newman, J., Noel, A., Chen, R., \& Matsopoulos, A. S. (1998). Temperament, selected moderating variables and early reading achievement. Journal of School Psychology, 36(2), 215-232. https://doi.org/10.1016/S0022-4405(98)00006-5

Ready, D., LoGerfo, L., Burkam, D., \& Lee, V. (2016, June 4). Explaining girls' advantage in kindergarten literacy learning: Do classroom behaviors make a difference? The Elementary School Journal, 106(1), 21-38.

Roebers, C. M., Röthlisberger, M., Cimeli, P., Michel, E., \& Neuenschwander, R. (2011). School enrolment and executive functioning: A longitudinal perspective on developmental 
changes, the influence of learning context, and the prediction of pre-academic skills. European Journal of Developmental Psychology, 8(5), 526-540.

https://doi.org/10.1080/17405629.2011.571841

Ryan, R. M., \& Deci, E. L. (2000). Self-determination theory and the facilitation of intrinsic motivation, social development, and well-being. American Psychologist, 55(1), 68-78. https://doi.org/10.1037/0003-066X.55.1.68

Sasser, T. R., Bierman, K. L., \& Heinrichs, B. (2015). Executive functioning and school adjustment: The mediational role of pre-kindergarten learning-related behaviors. Early Childhood Research Quarterly, 30, 70-79. https://doi.org/10.1016/j.ecresq.2014.09.001

Schmerse, D. (2020). Preschool quality effects on learning behavior and later achievement in Germany: Moderation by socioeconomic status. Child Development, 91(6), 2237-2254. https://doi.org/10.1111/cdev.13357

Smiley, P. A., \& Dweck, C. S. (1994). Individual differences in achievement goals among young children. Child Development, 65(6), 1723-1743. https://doi.org/10.1111/j.14678624.1994.tb00845.x

Spinath, B., \& Spinath, F. M. (2005). Development of self-perceived ability in elementary school: The role of parents' perceptions, teacher evaluations, and intelligence. Cognitive Development, 20(2), 190-204. http://dx.doi.org/10.1016/j.cogdev.2005.01.001

Sung, J., \& Wickrama, K. A. S. (2018). Longitudinal relationship between early academic achievement and executive function: Mediating role of approaches to learning. Contemporary Educational Psychology, 54, 171-183. https://doi.org/10.1016/j.cedpsych.2018.06.010 
Torpey, D. C., Hajcak, G., Kim, J., Kujawa, A., \& Klein, D. N. (2012). Electrocortical and behavioral measures of response monitoring in young children during a go/no-go task. Developmental Psychobiology, 54(2), 139-150. https://doi.org/10.1002/dev.20590

van Loon, M., de Bruin, A., Leppink, J., \& Roebers, C. (2017). Why are children overconfident? Developmental differences in the implementation of accessibility cues when judging concept learning. Journal of Experimental Child Psychology, 158, 77-94. https://doi.org/10.1016/j.jecp.2017.01.008

Vitiello, V. E., \& Greenfield, D. B. (2017). Executive functions and approaches to learning in predicting school readiness. Journal of Applied Developmental Psychology, 53, 1-9. https://doi.org/10.1016/j.appdev.2017.08.004

Vitiello, V. E., Greenfield, D. B., Munis, P., \& George, J. (2011). Cognitive flexibility, approaches to learning, and academic school readiness in Head Start preschool children. Early Education and Development, 22(3), 388-410. https://doi.org/10.1080/10409289.2011.538366

Wigfield, A., Eccles, J. S., Schiefele, U., Roeser, R. W., \& Davis-Kean, P. (2007). Development of Achievement Motivation. In Handbook of Child Psychology. American Cancer Society. https://doi.org/10.1002/9780470147658.chpsy0315 